www.jmscr.igmpublication.org Impact Factor 5.244

Index Copernicus Value: 83.27

ISSN (e)-2347-176x ISSN (p) 2455-0450

crossref DOI: _https://dx.doi.org/10.18535/jmscr/v4i12.09

Journal Of Medical Science And Clinical Research

\title{
Benign Fibrous Histiocytoma of the Back - A Diagnostic Dilemma
}

\section{Authors}

\section{Dr Gaurav Batra ${ }^{1}$, Dr Iresh Shetty ${ }^{2}$, Dr Aditya Lad ${ }^{3}$, Dr Ishant Rege ${ }^{4}$}

${ }^{1}$ MBBS, M.S. General Surgery (Final Year Resident), Dr. D.Y.Patil Medical College, Hospital and Research Centre, Pimpri, Pune-411018

Email: dr.gauravbatra@gmail.com,Contact: +919960999360

${ }^{2}$ MBBS, M.S. General Surgery (Second Year Resident), Dr. D.Y.Patil Medical College, Hospital and

Research Centre, Pimpri, Pune-411018

Email: ireshshetty@gmail.com, Contact: +917030738686

${ }^{3}$ MBBS, M.S. General Surgery (Second Year Resident), Dr. D.Y.Patil Medical College, Hospital and

Research Centre, Pimpri, Pune-411018

Email: adityaplad@gmail.com, Contact: +917030742828

${ }^{4}$ MBBS, M.S. General Surgery (Final Year Resident), Dr. D.Y.Patil Medical College, Hospital and Research Centre, Pimpri, Pune-411018

Email: micks.ishant@gmail.com, Contact: +919881130004

Corresponding Author

\section{Dr Iresh Shetty, MBBS, M.S. General Surgery}

Second Year Resident, Dr.D.Y.Patil Medical College, Hospital and Research Centre, Pimpri, Pune-411018;

Email: ireshshetty@gmail.com, Contact:+917030738686

\begin{abstract}
In this article, we present a case of a 40 year old male with complaints of swelling over right side of back since two months, with FNAC suggestive of spindle cell tumour arising from the ribs. Patient underwent wide local excision and the final histopathological report turned out to be benign fibrous histiocytoma.

The benign fibrous histiocytoma (BFH) is a mesenchymal tumour that has been described as a benign neoplasm composed of fibroblasts and histiocytes arising in the cutaneous and noncutaneous soft tissues. Pathologic analysis and diagnosis of Benign Fibrous Histiocytoma is often challenging and is based on a combination of light microscopy and immunohistochemistry. The treatment of choice is the complete resection of tumour, with an excellent prognosis and recurrence rate of almost zero.

The aim of this case report is to bring to the notice of the reader that the diagnosis of benign fibrous histiocytoma is one of exclusion and with attention to the clinical scenario, careful evaluation the histopathological morphologic features, one can work through such difficult cases to arrive at the correct diagnosis.

Keywords: Benign fibrous histiocytoma, Spindle cell tumour, tumour of the rib.
\end{abstract}

\section{INTRODUCTION}

The benign fibrous histiocytoma (BFH) is a mesenchymal tumour that has been described as a benign neoplasm composed of fibroblasts and histiocytes arising in the cutaneous and noncutaneous soft tissues. BFH is seen mainly in adults and most frequently in young and middle aged women. It is most commonly confused with spindle cell tumour. 


\section{JMSCR Vol||04||Issue||12||Page 14328-14331||December}

Benign fibrous histiocytoma (BFH) of the bone is a rare tumor which most commonly involves the wing of the ilium. Patients range from 5 to 75 years in age and no sex predilection has been noticed. Until recently BFH was considered to be a variant of metaphyseal fibrous defect (including fibrous cortical defect, non-ossifying fibroma etc.). However, based on radiological and clinical features BFH has now been assigned a separate category with different prognostic implications ${ }^{1,2}$. Only about 70 cases of BFH have been reported in the literature so far $^{2}$. We report a BFH of the rib in a 40 year-old male.

\section{CASE REPORT}

A 40 year old male patient presented to surgical OPD, with slow growing swelling over right side of back since 2 months, associated with dull aching pain. Examination revealed a $6 \times 5 \mathrm{~cm}$ swelling over posterolateral portion of right 11th and 12th rib extending up to the anterior axillary line. There was no history of weight loss/ discharge/lymphadenopathy, or similar complaints in the family. The swelling was mobile in horizontal plane and was tender on deep palpation. FNAC was suggestive of low grade spindle cell tumour.. USG swelling was suggestive of cold abscess/neoplasm. Local MRI posterolateral chest wall (plain and contrast) revealed 3.8x4.7x5.2 cm lesion in posterolateral portion of right 11 th and 12 th ribs suggestive of neoplastic etiology. Patient underwent wide local excision. The 10th, 11th and 12 th rib were excised till the margin was free of tumour. Pleural and peritoneal cavity were opened and there was no evidence of metastasis. The specimen was sent for histo-pathological examination which was suggestive of benign fibrous histiocytoma. Patient has been asymptomatic during a follow-up period of 6 months.

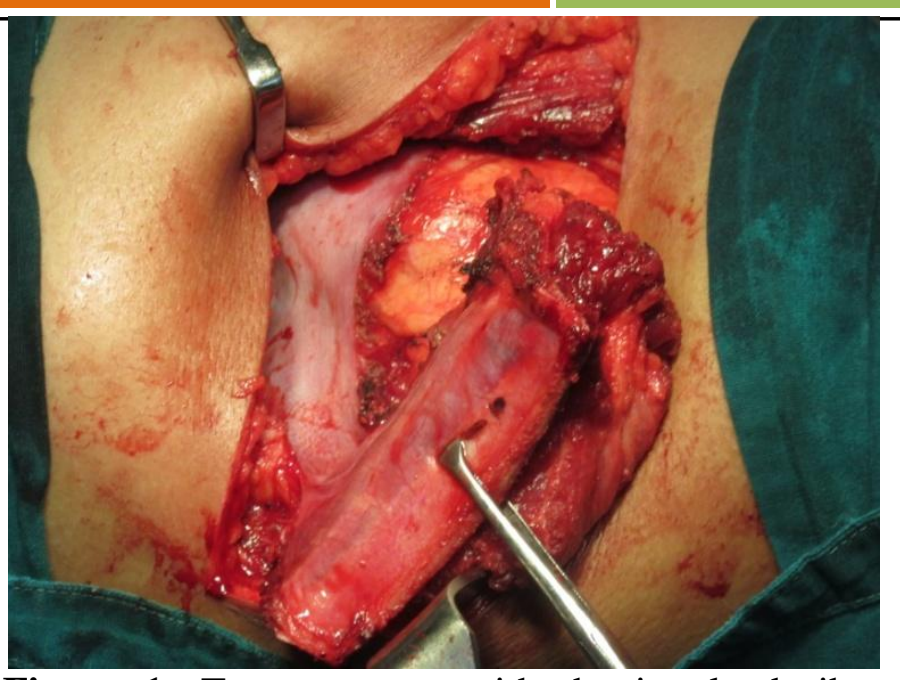

Figure 1: Tumour mass with the involved rib intraoperatively

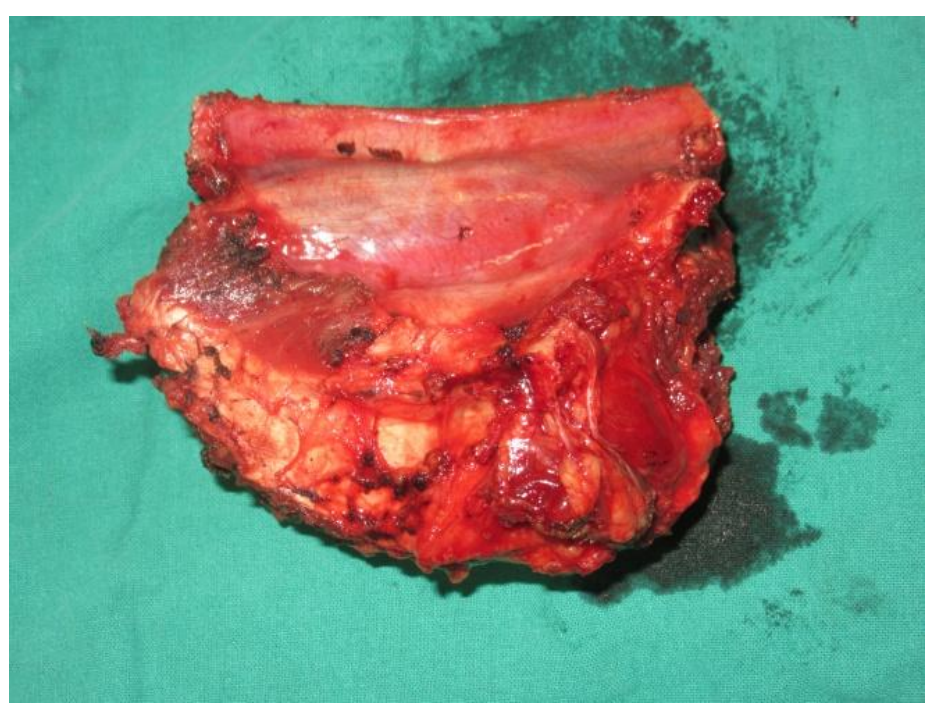

Figure 2: Excised specimen of tumour mass with rib

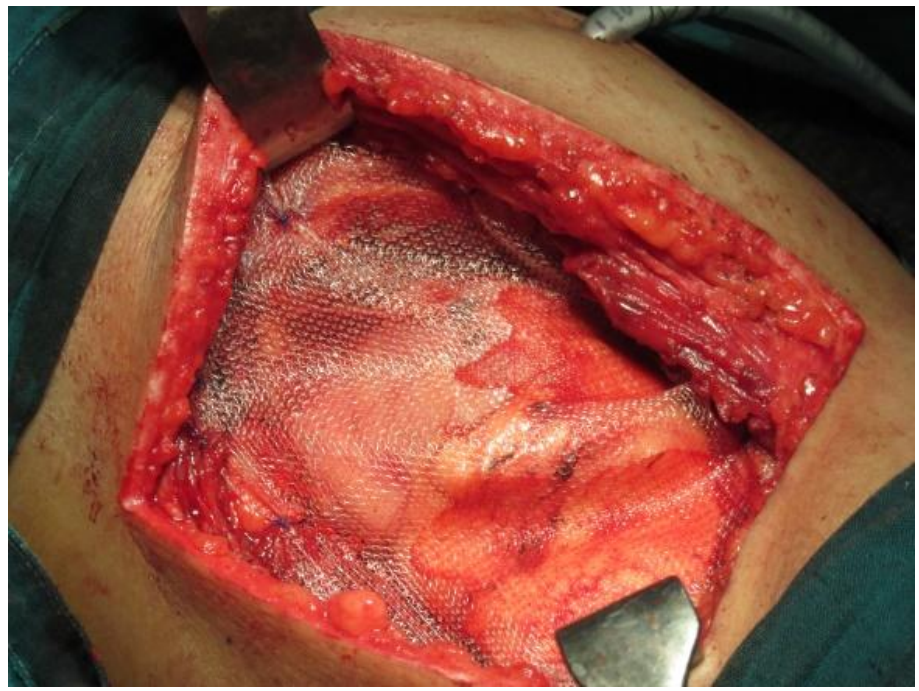

Figure 3: Mesh placed in the deficit space 


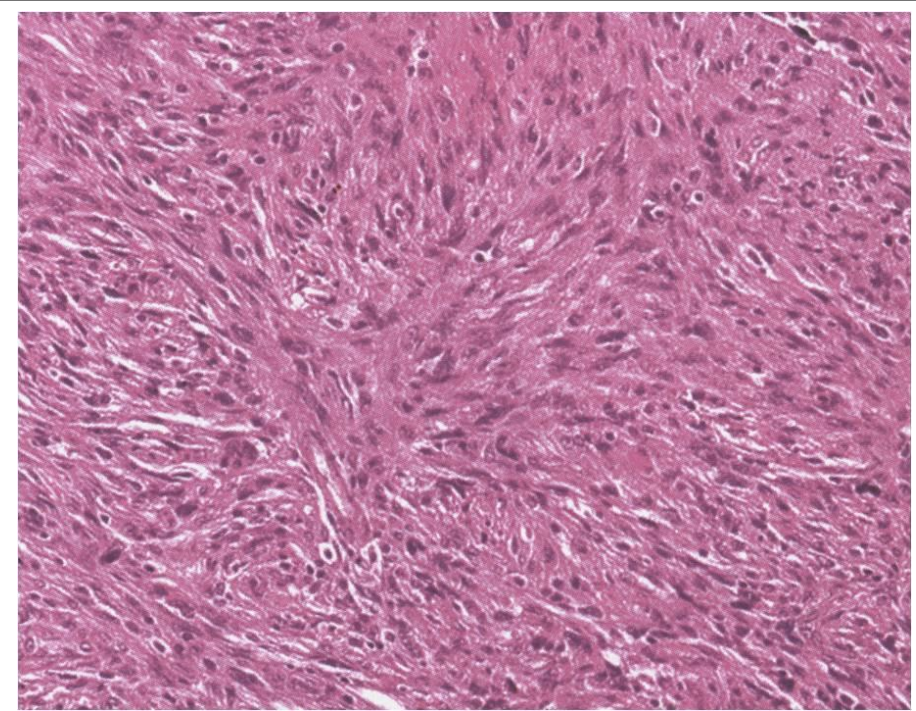

Figure 4: HPE s/o benign fibrous histiocytoma

\section{DISCUSSION}

Pathologic analysis and diagnosis of Benign Fibrous Histiocytoma is often challenging and is based on a combination of light microscopy and immunohistochemistry. Histopathologically, BFH typically shows a biphasic cell population of histiocytes and fibroblasts. The treatment of choice is the complete resection of tumour, with an excellent prognosis and recurrence rate of almost zero.

Benign fibrous histiocytoma (BFH) is a relatively common and well characterized soft tissue lesion. It occurs rarely in bone, approximating to $1 \%$ of all benign bone tumors. ${ }^{7}$

Non-ossifying (non-.osteogenic) fibroma and fibrous cortical defect (seen in subjects ranging from 2-20 years in age) are in general clinically silent, predominantly occur in the long bones of the lower limbs and are usually discovered on roentgenograms for incidental reasons 1,3 . They are not trueneoplasms but are considered to be developmental defects. Their rarity in children less than 2 years of age is consistent with the belief that muscle pull during weight bearing and walking is important intheir prognosis. Their infrequency in adults supports the concept that most lesions heal by being replaced by normal bone $^{4}$. BFH (fibroxanthoma) on the other hand is considered by most people to be a tumor with different clinical and radiological features ${ }^{1,2}$. The exact nature of BFH remains controversial, benign variant of malignant fibrous histiocytoma. adult NOF. regressive form of giant cell tumor and solid aneurysmal bone cyst being the possibilities offered by sonic of the authors ${ }^{1}$.Almost all the reported cases of BFH (only about 70 cases uptil now) have occurred in patients older than 20 years of age and many were accompanied by pain. The most common site involved is the ilium, followed by the femur, vertebrae, tibia and ribs (six cases) ${ }^{2}$. The importance of differentiating between NOF and $\mathrm{BFH}$ lies in the fact that $\mathrm{BFH}$ has a tendency to recur after curettage, while NOF does not. Additionally BFH has been known to behave in an aggressive manner with a potential for local spread and distant dissemination ${ }^{2,4}$. Most histologic features including mitotic rate do not appear to correlate with recurrence ${ }^{2}$. The use of the terms xanthofibroma, fibroxanthorna and xanthoma etc. is rather ambiguous and confusing, having been used interchangeably with $\mathrm{BFH}$ as well as $\mathrm{NOF}^{2-4}$.

The functional markers for identification of histiocyte (tissue macrophage) include immune phagocytosis, surface receptors for complement and for $\mathrm{Fc}$ portion of $\mathrm{IgG}$, and presence of lysosomal enzymes. ${ }^{5,6}$

Radiologically both NOF and BFH show a lytic appearance. however BFH usually also displays sclerosis and may rarely show destruction of cortex and invasion into adjacent soft tissue $e^{1,2}$. Giant celltumor, giant cell reparative granuloma, eosinophilic granuloma, osteosarcorna etc. are all included inthe differential diagnosis. In effect therefore, the diagnosis of $\mathrm{BFH}$ is one of exclusion $^{2}$.

\section{CONCLUSION}

The prognosis of BFH is excellent with wide local excision as definitive treatment. With attention to the clinical scenario, careful evaluation the H\&E morphologic features, one can work through these difficult cases to arrive at the correct diagnosis.

CONFLICT OF INTEREST: None 


\section{REFERENCES}

1. Hamada, T. Benign Fibrous Histiocytoma of the Femur, Review of three cases, Skeletal Radiol.,1996:25:25 -29.

2. Fechner, RE, Mills. SE. Tumours of the bones and joints in Atlas of tumor pathology, $\quad 3^{\text {rd }}$ series. Washington DC fascicle 8, AF.I.P..1992, pp.161-163.

3. Ackermans Surgical pathology.vol. 11.eighth edition, Ed: Juan Rosai, 1995. pp. 1979-1981.

4. Diagnosis of bone and joint disorders. Resnick, Volume 6, 3rd edition. 1995, Philadelphia W.B Saunders Company.pp 3767-3785.

5. Parker JW. Immunologic basis for the redefinition of malignant lymphomas. American Journal ofClinical Pathology 1979; 72:670-686.

6. Van Furth R. Cells of the mononuclear phagocyte system: nomenclature in terms of sites and conditions. In: van Furth R, ed. Mononuclear Phagocytes: Functional Aspects, Part I . Hague: MartinusNijhoff, 1980; 1-30.

7. Kulkarni N. Benign fibrous histiocytoma of bone: A case report; IJCRI 2013;4(4):224-227. 